\title{
Clinical guidelines on antidepressant withdrawal urgently need updating
}

\author{
James Davies reader ${ }^{1}$, John Read professor ${ }^{2}$, Michael P Hengartner senior lecturer ${ }^{3}$, Fiammetta \\ Cosci associate professor ${ }^{4}$, Giovanni Fava professor ${ }^{5}$, Guy Chouinard professor ${ }^{6}$, Jim van Os \\ professor $^{7}$, Antonio Nardi professor ${ }^{8}$, Peter Gøtzsche professor ${ }^{9}$, Peter Groot researcher ${ }^{10}$, Emanuela \\ Offidani assistant professor ${ }^{11}$, Sami Timimi visiting professor ${ }^{12}$, Joanna Moncrieff reader ${ }^{13}$, \\ Marcantonio Spada professor ${ }^{14}$, Anne Guy researcher ${ }^{15}$
}

\begin{abstract}
1'Department of Life Sciences, University of Roehampton, London SW15 4JD, UK; ${ }^{2}$ School of Psychology, University of East London, London, UK; ${ }^{3}$ School of Applied Psychology, Zurich University of Applied Sciences, Zurich, Switzerland; ${ }^{4}$ Department of Health Sciences, University of Florence, Florence, Italy; ${ }^{5}$ School of Medicine and Biomedical Sciences, University at Buffalo, Buffalo, NY, USA; ${ }^{6}$ Psychiatry Department, University of Montreal, Montreal, Canada; ${ }^{7}$ Department of Psychiatry and Psychology, Maastricht University Medical Centre, Maastricht, Netherlands; ${ }^{8}$ Institute of Psychiatry, Federal University of Rio de Janeiro, Rio de Janeiro, Brazil; ${ }^{9}$ Institute for Scientific Freedom, Copenhagen, Denmark; ${ }^{10}$ Department of Psychiatry and Neuropsychology, Maastricht University, Maastricht, Netherlands; ${ }^{11}$ Department of Psychology, Pennsylvania State University, University Park, PA, USA; ${ }^{12}$ School of Health and Social Care, University of Lincoln, Lincoln, UK; ${ }^{13}$ Division of Psychiatry, University College London, London, UK; ${ }^{14}$ School of Applied Sciences, London South Bank University, London, UK; ${ }^{15}$ All-Party Parliamentary Group for Prescribed Drug Dependence, Houses of Parliament, London, UK
\end{abstract}

In February 2018 the international debate on antidepressant withdrawal was reignited. ${ }^{1-4}$ In response to a letter published in the Times by Davies et al on the benefits and harms of antidepressants, ${ }^{1}$ the Royal College of Psychiatrists publicly stated that, "[for] the vast majority of patients, any unpleasant symptoms experienced on discontinuing antidepressants have resolved within two weeks of stopping treatment."

To support this claim the college referred to guidelines from the National Institute for Health and Care Excellence (NICE), which state that "[withdrawal] symptoms are usually mild and self-limiting over about 1 week."

When Davies et al issued a freedom of information request to NICE asking for the evidence for its one week claim NICE was able to provide only two short review articles, neither of which supports the one week claim, although both cite numerous sources that contradict it. ${ }^{6}$

We think that NICE's current position on antidepressant withdrawal (first established in 2004) not only was advanced on insufficient evidence but is now widely countered by subsequent research. Several studies, using a range of methods, show that many people experience withdrawal for longer than one week-for example, for over two weeks in 55\% of patients, ${ }^{7}$ at least six weeks in $40 \%,{ }^{8}$ at least 12 weeks in $25 \%,{ }^{9}$ and one to 13 weeks in $58 \%{ }^{10}$ - with other studies finding mean durations of 11 days $^{11}$ and 43 days. ${ }^{12}$

Examples of longer durations, of more than a year, are reported in two recent community samples of people experiencing difficulties with withdrawal-by $38.6 \%(\mathrm{n}=185)^{13}$ and for a mean duration of 90.5 weeks $(n=97){ }^{14}$

Systematic reviews of withdrawal also concur, and one of the largest concludes that withdrawal symptoms "typically ensued within a few days from discontinuation and lasted a few weeks, also with gradual tapering. Late onset and/or a longer persistence of disturbances occurred as well." ${ }^{15}$ Another stated that "[withdrawal reactions] typically occur within a few days from drug discontinuation and last a few weeks ... many variations are possible, including late onset and/or longer persistence of disturbances." ${ }^{16}$

The most recent systematic review, by Davies and Read, also concluded, on the basis of 14 studies of varied methods, that around half of users experience withdrawal when trying to stop or reduce antidepressant treatment, that nearly half of those experiencing withdrawal $(46 \%)$ report it as severe, and that reports of symptoms lasting several months are common in many recent studies (see examples of duration above). ${ }^{17}$

That the evidence base contradicts NICE's official position on antidepressant withdrawal raises concerns for the substantial 
number of antidepressant users who will experience withdrawal for a longer duration than current guidelines recognise.

Assuming that doctors abide by such guidelines, we believe that many people may have their antidepressant withdrawal misdiagnosed - for example, as relapse or as a failure to respond to treatment-with antidepressants being reinstated, switched, or increased in dose as a result.

These practices, if routinely enacted, would help partly explain why the average time a person spends taking antidepressants has doubled in the UK since the guidelines were introduced in $2004,{ }^{18}{ }^{19}$ why antidepressant prescriptions are rising overall, and why patients regularly report that their withdrawal is not properly acknowledged, understood, and managed by doctors. ${ }^{2021}$ In addition, the pooled results of two recent surveys showed that under $2 \%$ of around 3000 patients were able to recall being told anything about withdrawal effects, dependence, or potential difficulties in discontinuing treatment. ${ }^{22} 23$

It is worrying that antidepressants are causing withdrawal effects that can be long lasting and severe and that this is not being sufficiently recognised by current clinical guidelines-and, by extension, many prescribers. NICE is now in the process of updating its depression guidelines, and we call on it and the royal colleges to revise their practice guidelines and recommendations to bring them in line with the scientific evidence base.

\section{Competing interests: None declared.}

1 Davies J, Moncrieff J, Kinderman P, et al; Council for Evidence-Based Psychiatry. Stigma and efficacy of taking antidepressants. Letter to the editor. Times 2018 Feb 23. https:// www.thetimes.co.uk/article/stigma-and-efficacy-of-taking-antidepressants-0zvsg560x.

2 Baldwin D, Burns W. Pills for depression. Letter to the editor. Times 2018 Feb 24. https: //www.thetimes.co.uk/article/86afb2fc-18c7-11e8-a427-78e8af199a96.

3 Hengartner MP. Rapid response to: Adlington $\mathrm{K}$, Pop a million happy pills? Antidepressants, nuance, and the media. BMJ 2018. https://www.bmj.com/content/360/ bmj.k1069/rr-1.

4 Davies J, Read J, Hengartner M, et al. Rapid response to: lacobucci G, NHS prescribed record number of antidepressants last year. BMJ 2019. https://www.bmj.com/content/364/ bmj.l1508/rr-4

5 National Institute for Health and Care Excellence. Depression in adults: recognition and management. 2009. https://www.nice.org.uk/guidance/cg90/resources/depression-inadults-recognition-and-management-pdf-975742638037.

6 Davies J, Read J. A systematic review into the incidence, severity and duration of antidepressant withdrawal effects: Are guidelines evidence-based? Addict Behav 2018;2018:4; [epub ahead of print]. 10.1016/j.addbeh.2018.08.027. 30292574
7 Perahia DG, Kajdasz DK, Desaiah D, Haddad PM. Symptoms following abrupt discontinuation of duloxetine treatment in patients with major depressive disorder. $J$ Affect Disord 2005;89:207-12. 10.1016/j.jad.2005.09.003 16266753

8 Zajecka J, Fawcett J, Amsterdam J, etal . Safety of abrupt discontinuation of fluoxetine: a randomized, placebo-controlled study. J Clin Psychopharmacol 1998;18:193-7. 10.1097/00004714-199806000-00003 9617977

9 Royal College of Psychiatrists. Coming off antidepressants. 2012. http://www.rcpsych.ac. uk/healthadvice/treatmentswellbeing/antidepressants/comingoffantidepressants.aspx. (Accessed Feb 2018.)

10 Black K, Shea C, Dursun S, Kutcher S. Selective serotonin reuptake inhibitor discontinuation syndrome: proposed diagnostic criteria. J Psychiatry Neurosci 2000;25:255-61.10863885

11 Price JS, Waller PC, Wood SM, MacKay AV. A comparison of the post-marketing safety of four selective serotonin re-uptake inhibitors including the investigation of symptoms occurring on withdrawal. Br J Clin Pharmacol 1996;42:757-63. 10.1046/j.1365-2125.1996.00498.x 8971432

12 Narayan V, Haddad PM. Antidepressant discontinuation manic states: a critical review of the literature and suggested diagnostic criteria. J Psychopharmacol 2011;25:306-13. 10.1177/0269881109359094 20156925

13 Davies J, Pauli R, Montagu L. Antidepressant withdrawal: a survey of patients' experience by the All-Party Parliamentary Group for Prescribed Drug Dependence. 2018. http:// prescribeddrug.org/wp-content/uploads/2018/10/APPG-PDD-Survey-of-antidepressantwithdrawal-experiences.pdf.

14 Stockmann T, Odegbaro D, Timimi S, Moncrieff J. SSRI and SNRI withdrawal symptoms reported on an internet forum. Int J Risk Saf Med 2018;29:175-80. 10.3233/JRS-180018 29758951

15 Fava GA, Benasi G, Lucente M, Offidani E, Cosci F, Guidi J. Withdrawal symptoms after serotonin-noradrenaline reuptake Inhibitor discontinuation: systematic review. Psychother Psychosom 2018;87:195-203. 10.1159/000491524 30016772

16 Fava GA, Gatti A, Belaise C, Guidi J, Offidani E. Withdrawal symptoms after selective serotonin reuptake inhibitor discontinuation: a systematic review. Psychother Psychosom 2015;84:72-81. 10.1159/000370338 25721705

17 Davies J, Read J. A systematic review into the incidence, severity and duration of antidepressant withdrawal effects: Are guidelines evidence-based? Addict Behav 2018 10.1016/j.addbeh.2018.08.027. 30292574

18 NHS Digital. Prescriptions dispensed in the community - Statistics for England, 2006-2016. https://digital.nhs.uk/data-and-information/publications/statistical/prescriptions-dispensedin-the-community/prescriptions-dispensed-in-the-community-statistics-for-england-20062016-pas.

19 Kendrick T. Long-term antidepressant treatment: Time for a review? Prescriber 2015;26:7-810.1002/psb.1389.

20 Davies J, Pauli G, Montagu L. A survey of antidepressant withdrawal reactions and their management in primary care. Report from the All Party Parliamentary Group for Prescribed Drug Dependence. 2018. http://prescribeddrug.org/wp-content/uploads/2018/10/APPGPDD-Survey-of-antidepressant-withdrawal-experiences pdf.

21 Cartwright C, Gibson K, Read J, Cowan O, Dehar T. Long-term antidepressant use: patient perspectives of benefits and adverse effects. Patient Prefer Adherence 2016;10:1401-7. 10.2147/PPA.S110632 27528803

22 Read J, Cartwright C, Gibson K. How many of 1829 antidepressant users report withdrawal symptoms or addiction? Int J Ment Health Nurs 2018. 10.1111/inm.12488.

23 Read J, Williams J. Adverse effects of antidepressants reported by a large international cohort: emotional blunting, suicidality, and withdrawal effects. Curr Drug Saf 2018;13:176-86. 10.2174/1574886313666180605095130 29866014

Published by the BMJ Publishing Group Limited. For permission to use (where not already granted under a licence) please go to http://group.bmj.com/group/rights-licensing/ permissions 